\title{
OFERTA DO ENSINO FUNDAMENTAL EM SÃO PAULO: UM NOVO MODELO
}

\author{
ThereSA Adrião*
}

RESU M 0 : Este trabalho propõe-se a refletir sobre o conteúdo e as implicações, para a oferta da educação básica, de duas das principais me didas que sustentaram a reforma da educação paulista implantada pelo primeiro governo de M ario Covas (1995-1998). São elas: a reorganização das escolas da rede estadual e a política de municipalização do ensino fundamental mediante a adoção de convênios.

Palavras chave: D escentralização. M unicipalização. Reforma educacional. G estão educacional.

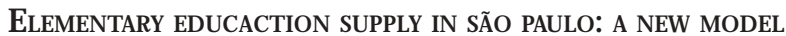

ABST RACT : This paper is aimed at fostering a reflection about the contents of two educational measures and their implications for basic education supply in the state of São Paulo. They are the reorganization of schools within the state educational system and the policy of municipalization of elementary education through the adoption of partnerships, two of the main measures that supported the educational reform implemented by governor $\mathrm{M}$ ário $\mathrm{C}$ ovas between 1995 and 1998.

Key words: Decentralization. M unicipalization. Educational reform. Educational administration.

* D outora em Educação e professora do D epartamento de Educação da U niversidade Estadual Paulista (UnESP, Rio Claro). E-mail: theadriao@yahoo.com.br 
E

ste artigo resulta da análise do conteúdo presente nas medidas propostas pelos órgãos do sistema estadual de educação do estado de São Paulo, em especial pela Secretaria Estadual de Educação (seE) e pelo Conselho Estadual de Educação de São Paulo (CEe), com vistas a implementar as diretrizes educacionais defendidas pelo governo em exercício para o período de 1995-1998: racionalização e reforma da estrutura administrativa da Secretaria, descentralização e desconcentração dos recursos e mudanças no padrão de gestão.

0 objetivo foi selecionar aquelas mais evidentemente direcionadas a alterar a função e o modelo de organização que caracterizavam o funcionamento do sistema educacional paulista, principalmente quanto à oferta do ensino fundamental. Para tanto, destacam-se as ações desencadeadas a partir do que ficou conhecido como Reorganização das escolas da rede estadual de ensino, que definiram o novo perfil organizacional da SEE ao alterar o padrão de oferta da educação básica, tendo por ponto de partida mudanças na organização das próprias escolas. Complementarmente, apresentam-se os mecanismos adotados para a indução dos convênios entre 0 governo do estado e os municípios, genericamente denominados de parcerias, que redundaram na municipalização do ensino fundamental, inaugurando um novo padrão de atendimento a esta demanda.

Com um discurso fundado na necessidade de alteração no modelo de gestão e no perfil de oferta da educação básica, o primeiro governo de M ario Covas, tendo a professora Teresa Roserley N eubauer da Silva à frente da Secretaria da Educação, divulga, em 22 de março de 1995, as Diretrizes Educacionais para o Estado de São Paulo relativas ao período de janeiro de 1995 a dezembro de 1998. Espelhando o espírito de sua época, a posição do governo assemelha-se às orientações reformadoras para a educação apresentadas, a partir de meados dos anos de 1980, por diferentes autores e agências internacionais de financiamento, como o Banco M undial, se não suficientemente analisadas, ao menos bastante divulgadas no período.

Correndo o risco da simplificação, para efeito do aqui em destaque, tais reformas, conservadoras - nas palavras de M arcio da Costa (1995) -, estabeleciam uma relação direta de causa e efeito entre o modelo de gestão da educação na América Latina e a baixa qualidade da educação obrigatória. Propunham, em sintonia com a "nova ordem", uma mudança no papel atribuído ao Estado para a oferta e manutenção 
da educação. 0 conteúdo, explicitamente propagado, sugeria que o Estado deixasse de ser o responsável prioritário pelo financiamento e manutenção da educação básica e passasse a exercer a função de "gestor" dessa mesma educação (Peroni, 2003; Adrião, 2001).

Para tanto, ao invés de investir diretamente recursos públicos e manter um aparato administrativo que oferecesse os serviços educacionais, caberia ao Estado induzir "parceiros" (sociedade civil, empresas, níveis inferiores de governos etc.) a se responsabilizarem por essa oferta, resguardando-se a tarefa de definir o produto educacional a ser atingido e os mecanismos para aferição da qualidade desse produto. Para esse fim, além das mudanças em todo 0 aparato político e institucional da SEE, cujas implicações para todos os sistemas de ensino do Estado fogem ao proposto neste trabalho, duas medidas fundaram o novo cenário do ensino público paulista: a reorganização das escolas da rede estadual e a generalização das parcerias com os municípios.

No caso do estado de São Paulo, a mudança na gestão da educação básica, implantada pelo governo em exercício naquele período, significou a criação das condições para a municipalização do ensino fundamental, posteriormente reforçada pela EC-14/96, que criou 0 FUNDEF.

\section{Reorganização das escolas: divisão do ensino fundamental}

Publicada a Resolução favorável do CEE, em 21 de novembro de 1995, a SEe implanta o Programa de Reorganização das Escolas da Rede Pública Estadual (D ecreto n. 40.473), pelo qual foi realizada uma das mais profundas mudanças na rede paulista de ensino.

As alterações propostas, das quais a mais evidente é a oferta de equipamentos escolares diferentes das quatro primeiras e das quatro últimas séries do ensino fundamental e do ensino médio, são baseadas em um conjunto de justificativas. A primeira delas, ao afirmar que a escolarização obrigatória de oito anos atingia apenas 50\% dos ingressantes, parecia buscar evidências de que a incapacidade da rede em atender dignamente à população, que a ela teve acesso a partir da década de 1970, resultava do próprio mecanismo que permitiu o acesso dessa população à escolarização: implantação da escola obrigatória de oito anos.

0 utra justificativa, aparentemente técnica, afirmava que a escola que atende a todas as oito séries do ensino fundamental "comprovadamente 
gera problemas pedagógicos sérios" (grifo meu), posição similar à encontrada no parecer do ceE sobre a medida. Essa crítica genérica à escola de oito anos soma-se à outra, não menos ambígua, segundo a qual experiências já consagradas confirmavam a tese de que agrupamentos de alunos com idades próximas seriam mais producentes para o trabalho pedagógico.

Tais "experiências" são apresentadas à rede no documento M udar para melhorar: uma escola para a criança outra para o adolescente, por meio de modelos de organização da educação básica em 14 países, tão díspares quanto Suécia e Chile. Apesar dos modelos variarem em sua organização, a seleção buscava demonstrar que apenas o Brasil possuía um nível de escolaridade composto por oito séries consecutivas. O C hile, por exemplo, teria três ciclos de quatro anos (o que não corresponderia à verdade) e a Suécia dois ciclos de seis anos. Parece, pelos exemplos arrolados, que a SEE não buscava questionar a presença das oito séries em um único prédio, uma vez que o documento não se referia ao local utilizado pelos diferentes países para a oferta dos diferentes níveis de ensino, mas sim à existência das oito séries oferecidas por um mesmo sistema de ensino (SEE, 1995, p. 25).

0 objetivo, de acordo com o decreto, seria garantir a escolarização de oito anos e melhorar 0 atendimento pedagógico por meio da adoção de iniciativas como sala ambiente, laboratórios e espaços adequados às diferentes série/idade. Chama a atenção o detalhamento do modelo de escola que o governo desejava implementar, ao mesmo tempo em que divulgava a necessidade de ampliação da autonomia para as escolas, inclusive pedagógica, como condição para a melhoria da qualidade do ensino.

0 texto oficial caracterizava a rede de escolas estaduais como ociosa, dada a média de 33 alunos por professor.

Por último, a SEe fundamenta a necessidade da reorganização das escolas na caracterização de que os equipamentos não se adequavam ao alunado, em função da heterogeneidade etária deste último.

0 decreto define a organização das escolas da rede estadual em quatro modelos: o primeiro composto apenas pelos quatro primeiros anos do ensino fundamental, em escolas que funcionem, preferencialmente, em dois turnos; o segundo, por escolas constituídas pelos quatro últimos anos do ensino fundamental; o terceiro, por este último período de escolarização e mais o ensino médio; e o último apenas por escolas que oferecessem 0 ensino médio. 
0 governo comprometia-se a implementar gradativamente a mudança, respeitando as especificidades locais. No entanto, basta observar o percentual de $63 \%$ de escolas reorganizadas no período de um ano (1995 a 1996) para perceber a rapidez com que a medida foi conduzida. Ressalta-se que setores da sociedade civil organizada, como os sindicatos, e escolas de todo o estado manifestaram-se contrários à medida e, em alguns casos, tentaram suspendêla, por meio de medidas judiciais. Esse foi o caso da representação impetrada por um conjunto de educadores e pais de alunos de Ribeirão Preto junto à Promotoria da Infância e da Juventude daquela cidade. No mesmo sentido, manifestam-se o Fórum Estadual em D efesa da Escola Pública e o Fórum M unicipal em D efesa da Escola Pública do M unicípio de São Paulo, entidades que congregam diferentes setores organizados em torno da questão educacional.

Como fonte de informação e parâmetro para adequação da proposta de reorganização, segundo a Secretaria, foi distribuído às unidades escolares, ${ }^{1}$ no final de 1995, o manual para "orientação técnica - Educação paulista: corrigindo rumos. M udar para melhorar: uma escola para a criança e outra para 0 adolescente". 0 documento apresentava as "alternativas" experimentadas pelos municípios de Buritizal (com 2 escolas estaduais), Piraju (com 8 escolas estaduais) e Valinhos (com 17 escolas estaduais), tidos, pelo governo, como representativos das situações dos municípios do estado de São Paulo, ilustradas pela tabela a seguir:

\section{Tabela 1}

(R elação entre número de escolas e municípios)

\begin{tabular}{|l|l|}
\hline \multicolumn{1}{|c|}{$\begin{array}{c}\text { N úmero de escolas } \\
\text { estaduais }\end{array}$} & N úmero de municípios \\
\hline 1 & 116 \\
\hline 2 a 5 & 261 \\
\hline 6 a 10 & 104 \\
\hline 11 a 20 & 79 \\
\hline 21 a 50 & 48 \\
\hline 51 a 100 & 13 \\
\hline acima de 100 & 4 \\
\hline T otal & 625 \\
\hline
\end{tabular}

Fonte: SEE, 1995. O bs: não são computadas as escolas unidocentes. 
Pela tabela, nota-se que a maior parte dos municípios possuía entre 2 e 5 escolas. Apesar da ausência de dados a respeito do tamanho dessas escolas, é de se supor, inclusive por conta de informações da própria SEe, que seriam escolas pequenas. Tais condições, somadas - número reduzido de escolas com poucas salas -, podem ter causado dificuldades de acesso e locomoção para a população usuária, tendo em vista a reorganização imposta.

As alternativas versavam sobre a "criatividade" dos municípios-piloto na ocupação de "novos" espaços para atender às orientações de separar as diferentes séries da educação básica:

(...) destacam-se, por exemplo, o uso de equipamentos municipais (EM EI [E scola M unicipal de Educação I nfantil]) para abrigar classes de Ciclo Básico - CB, o uso de espaços comunitários para 0 atendimento do supletivo: transporte, pela municipalidade, dos alunos de 5a série em diante de escolas isoladas geograficamente (...), o uso diferenciado de espaços independentes em um mesmo estabelecimento etc. (SEE, 1995, p. 5)

A criatividade mencionada parecia pressupor a diminuição da oferta, pelos municípios, da educação infantil, uma vez que estes propunham 0 uso dos espaços destinados a esta modalidade de ensino para o oferecimento das séries iniciais do ensino fundamental, com a substituição das classes de préescola pelas de ensino fundamental. ${ }^{2}$ Esse mecanismo, generalizado nos municípios do interior paulista, redundou na criação de um híbrido de escolas de educação infantil e ensino fundamental, implicando a diminuição paulatina do atendimento da primeira etapa da educação básica. A tabela abaixo pode auxiliar a melhor perceber a situação:

\section{Tabela 2}

(N úmero de escolas por estrato de número de classes - 1994)

\begin{tabular}{|l|l|l|l|l|}
\hline \multicolumn{2}{|c|}{ 5a à 8a séries do ensino fundamental } & \multicolumn{2}{c|}{ Ensino médio } \\
\hline $\mathrm{n}$ - classes & $\mathrm{n}$ - escolas & $\%$ & $\mathrm{n}$ escolas & $\%$ \\
\hline 1 a 5 & 997 & 16,6 & 686 & 29,1 \\
\hline 6 a 10 & 1807 & 31,0 & 681 & 28,8 \\
\hline 11 a 15 & 1786 & 29 & 430 & 18,2 \\
\hline 16 e mais & 1369 & 7 & 564 & 23,9 \\
\hline
\end{tabular}

Fonte: CIE/SEE 
D e acordo com o manual, a redefinição da ocupação dos prédios deu-se, nestes municípios, a partir do cruzamento entre a demanda atendida por bloco de séries e o "tamanho" do prédio: escolas maiores para adolescentes e menores para crianças. No texto não há informações que indiquem preocupações da SEE quanto à distância entre a residência dos alunos e a escola de destino, quanto às dificuldades do quadro docente etc.

Em dezembro de 1995, o D ecreto n. 40.510 ampliou para 5 horas o trabal ho diário com os alunos do período diurno. No mesmo dia, pela Resolução n. 265, de 4/12/95, a SEE define a sistemática de "remanejamento" de alunos e professores para, no ano seguinte, implantar a reorganização das escolas: os alunos seriam remanejados para unidades escolares selecionadas de acordo com as propostas apresentadas pelas esferas governamentais locais.

A partir de janeiro de 1996, visando a "racionalizar e informatizar procedimentos relativos à autorização oficial anual para transformação de escolas, instalação, criação e extinção de classes", a seE passou a publicar a relação de unidades escolares (UES), com seus respectivos números de classes por grau e modalidade de ensino, a partir do que qualquer alteração na situação das escolas efetivar-seia apenas mediante "expressa autorização do titular da pasta".

Passado um ano da experiência da reorganização, pela Resolução $n$. 169, de 20/12/96, a Secretaria remete aos órgãos centrais de sua estrutura, as Coordenadorias, a sel eção das novas escolas a serem reorganizadas, observando que o remanejamento dos alunos, "sempre que possível", de veria ocorrer em áreas de "abrangência das escolas". M antém a mesma orientação sobre a quantidade de turnos e veda o funcionamento de classes de Suplência I e de préescola nos equipamentos da rede estadual.

0 processo de adequação da situação dos profissionais da educação continuou o mesmo do ano de 1995. O s professores, lotados em escolas reorganizadas, poderiam remover-se, por meio de processo de atribuição de aulas em 1997, fazendo inscrição na escola de destino para onde fossem remanejados os alunos/classes. Os especialistas e integrantes do quadro de apoio permaneceriam nas escolas.

É de se notar a diminuição drástica na quantidade total de escolas durante o período: de 6.783 unidades existentes em 1995, 5.919 encontravam-se em funcionamento no ano de 1998 e 864 escolas foram fechadas. Para Arelaro (1999, p. 87), 
(...) houve surpreendentemente redução do número de escolas estaduais (no total, 864), que por sua vez traduziriam a denúncia que tem sistematicamente sido feita de que, ao lado da argumentação positiva da redução dos períodos de funcionamento, deu-se, de forma concomitante, expressivo aumento do número de alunos em cada sala de aula, em todos os períodos de funcionamento escolar, com significativa redução no número de professores.

Como parte da avaliação do primeiro ano de governo, publicada pela revista Escriba, órgão do gabinete do governador, foi considerado "benefício da reorganização (...) [a] melhor utilização dos equipamentos com diminuição de 7.500 classes, desativação de 120 escolas e eliminação da construção de 1.400 novas salas de aula" (Escriba, 1996).

A base de dados utilizada para a reorganização das escolas resultou do cadastramento geral dos alunos do ensino fundamental e médio da rede estadual (D ecreto n. 40.290, de 31/08/95), iniciando ao final do primeiro ano de governo e coincidindo com o período de término do ano letivo. A justificativa presente no texto do decreto remetia a medida à necessidade de conhecer exatamente o número de alunos do estado de São Paulo para evitar a duplicidade de matrículas e a formação de classes ociosas.

Embora houvesse, na época, um movimento no sentido de reivindicar a realização de um censo escolar que pudesse apresentar dados educacionais mais confiáveis, a Secretaria optou por limitar-se a proceder ao levantamento do número de matrículas já existentes como fonte de informação ou legitimação para suas ações. Em função disso, os dados que subsidiaram a implementação da reorganização das escolas referiam-se apenas aos alunos já incluídos no processo de escolarização.

\section{Parcerias: nova divisão de responsabilidades?}

Articulado às mudanças apresentadas até aqui, o outro elemento a compor o conjunto de ações que alterou o modelo de gestão da educação no estado de São Paulo relaciona-se à adoção do mecanismo das parcerias para a oferta do ensino fundamental.

Embora a SEE adotasse os municípios como parceiros prioritários para a oferta do ensino fundamental, outras formas de "parceria" foram estimuladas e implantadas durante 0 período. Em geral, estas se referiam à participação da iniciativa privada na oferta de serviços até então reservados ao Estado. 
Foi com a Resolução n. 234, de 2 de outubro de 1995, que a parceria escola pública/setor privado passou a ser normalizada. Segundo a resolução, o estímulo às parcerias justificava-se em virtude da responsabilidade do estado na definição dos termos para a consolidação dos parceiros, pela importância da educação para o desenvolvimento econômico estadual e pela "necessidade de descentralizar e desconcentrar ações de forma a propiciar a autonomia de gestão a nível local".

As parcerias podem estar desenvolven do ações local izadas eabrangentes. Entende-se por ações localizadas aquelas que constituem iniciativas locais, ou seja, partem da base para o centro do Sistema da Secretaria. Exemplos: adoção de uma escola por empresa, investindo na preservação de seu patrimônio (pintura) ou na parte pedagógica. As ações abrangentes são iniciativas centralizadas, isto é, as ações ou projetos que envolvam uma parte significativa ou toda a Rede, com a participação de um ou mais parceiros. (SEE, 1999, disponível em: 〈http://www.educacao.sp.gov.br/projetos/parceria/>)

$\mathrm{N}$ a prática, incentivava-se que as escolas, por meio da Associação de Pais e M estres (APM S), desenvolvessem "atividades conjuntas com a comunidade", relativas à manutenção do prédio ou de equipamentos, aquisição de materiais, promoção de atividades culturais e de programa de capacitação da equipe escolar etc. A parceria deveria ser aprovada pelo Conselho Escolar (CE) e obedecer ao protocolo de intenções que integrava a resolução, além de estar condizente com as diretrizes da SEE.

$\mathrm{N}$ a divisão de papéis, definida pela resolução, caberia à secretaria apoiar mecanismos que promovessem, a partir da iniciativa das UES, projetos de parcerias descentralizadas, tendo em vista a sempre invocada autonomia da getãao. Seriam funções dos parceiros da sociedade civil: elaborar os projetos junto com a UE, aplicar recursos financeiros e eventualmente humanos para o desenvolvimento desses projetos e participar do gerenciamento dos recursos. As parcerias deveriam priorizar o provimento de re cursos financeiros, humanos e materiais e o fornecimento de mobiliário, equipamentos, livros para a biblioteca etc. A responsabilidade pela gestão dos recursos seria da APM.

O conteúdo do protocolo ilustra a tendência da política educacional aqui apresentada de descentralizar, para a effera da sociedade, responsabilidades pela manutenção e melhoria do ensino público. Parece que 0 estímulo à participação da população se desloca do âmbito dos processos decisórios para a esfera da manutenção física da escola, fortalecendo um 
discurso que co-responsabiliza o usuário pela qualidade, ou pela má qualidade, do serviço educacional, ao mesmo tempo em que se observa a diminuição da presença do estado na oferta desse mesmo serviço.

Além das parcerias entre escolas e setor privado, a presença de me canismos de convênio entre estado e município para a oferta da educação básica foi a tônica do processo de descentralização da oferta educacional aqui destacado.

I nicialmente, mantém-se a sistemática dos convênios entre o governo estadual e os municípios, recurso existente desde 0 início da década de 1980, como mecanismo para repassar aos municípios responsabilidades pela oferta educacional (Arelaro, 1999). Exemplo pode ser encontrado na Resolução SE n. 182, de 10 de julho de 1995, que dispõe sobre convênio com as prefeituras para o uso de material de apoio didático, por meio da instalação do Centro Integral de M aterial de Apoio D idático, de responsabilidade do município.

Também na perspectiva do estímulo à municipalização, é promulgada a Lei Estadual n. 9.143, ${ }^{3}$ de 9 de março de 1995, que fixa normas para criação, composição, atuação e funcionamento dos Conselhos M unicipais de Educação (CME). Por esta Lei, os Conselhos M unicipais passam a ter "caráter normativo, consultivo e deliberativo" e a integrar os sistemas municipais criados pelo executivo. Ao ceE cabe a fixação dos critérios e condições para delegação de competências aos CM ES, os quais, entre outras atribuições, devem colaborar com o poder público municipal na formulação da política educacional e na elaboração do plano municipal de educação (art. 40, inciso ॥). A Lei previa, também, a existência do Conselho Regional de Educação - englobando um ou mais municípios -, o qual deveria auxiliar na formulação das diretrizes para o desenvolvimento educacional da região.

Com vistas a formalizar os processos de constituição dos conselhos municipais e regionais de Educação, em 10 de maio de 1995 é homologada a D eliberação 9/95 do CEE. D entre as catorze atribuições dos CM ES previstas na deliberação, destacase a aprovação dos convênios de ação interadministrativa que envolvam o poder público municipal e as demais esferas do poder público ou setor privado (art. 2, inciso vII). As competências delegadas pelo CEE para OS CM ES referem-se ao ensino fundamental e à educação infantil. Porém, no caso de os municípios comprovarem 0 atendimento à demanda dessas modalidades de ensino, poderiam ser ampliadas para 0 ensino médio (art. 3). 
O utra medida, normalizando a transferência de ações do governo estadual para os municipais e para as escolas, encontra-se no $D$ ecreto $n$. 40.626, de 8 de janeiro de 1996, que autoriza a SEE a celebrar convênio

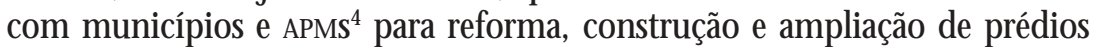
escolares, não implicando "obrigações financeiras específicas ao Estado".

$\mathrm{O} s$ anexos do decreto constituem-se de documentos sucintos e prescritivos a serem preenchidos pelos "parceiros", para o que prevêem a presença de duas testemunhas. Por eles, são fixadas as condições e as responsabilidades das partes: municípios, APM S e a SEE. As obrigações da SEE limitam-se ao acompanhamento técnico, à fiscalização e incorporação, junto à Procuradoria do Patrimônio I mobiliário, das alterações nos pré dios. Já aos municípios ou às Apms caberia a execução técnica e financeira dos convênios.

Porém, o estímulo à transferência do ensino fundamental para os municípios foi intensificado com o D ecreto n. 40.673, de 16 de fevereiro de 1996, que institui o Programa de Ação de Parceria Educacional Estado-M unicípio para atendimento do ensino municipal - municipalização, medida oficialmente justificada pela necessidade de se melhorar a qualidade e a eqüidade do ensino fundamental público, por meio da "distribuição mais adequada de responsabilidades entre Estado e municípios". O Programa foi

(...) lançado em abril de 1996, no Palácio dos Bandeirantes, ao reforçar os objetivos de esten der 0 acesso a toda a população infanto-juvenil ampliando os anos de permanência na escola (...). R eflete a convicção de intensificar o processo de descentralização do ensino, particularmente de 1 ạ a 4 a sé ries do Ensino Fundamental e com a institucionalização do Fundo de $\mathrm{M}$ anuten ção e D esenvolvimento de Ensino Fundamental e Valorização do $M$ agistério, eresponde aos princípios de racional ização e de otimização dos recursos, definindo a atuação e aplicação prioritária dos Estados e municípiosnesses graus de ensino. (Escriba, 1997, s/n)

Complementarmente, o programa era justificado pela necessidade de "fortalecer a autonomia do Poder M unicipal e o controle das atividades escolares pelas comunidades locais"; de promover a descentralização, "com base no princípio da responsabilização numa nova percepção do atendimento aos problemas que a sociedade apresenta" e, por fim, de atender aos artigos 240 e 249, parágrafos $1^{\circ}$ e e 2ㅇ, da Constituição do Estado. ${ }^{5}$ 
Levando isso em consideração e colocando em prática diretrizes governamentais já definidas em 1995, este decreto, na prática, induz à municipalização da rede estadual, em consonância, inclusive, com o espírito do FUNDEF, que viria a ser, posteriormente, instituído pela Lee Federal n. 9.424, de dezembro de 1996.

0 decreto, em seu artigo 1으, institui a parceria entre estado e município por meio de "ação conjunta" entre os respectivos executivos para de senvolver o ensino fundamental. Sua implantação seria gradativa e em função da adesão dos municípios para "assunção total ou parcial da rede pública estadual e da gestão educacional". D e acordo com documento de avaliação elaborado pelo próprio governo,

Em 1996, a partir do D ecreto n. 40.673, de 16/2/96, que instituiu 0 Programa de Ação de Parceria Educacional Estado-município para atendimento do ensino fundamental, foram firmados os primeiros convênios com 46 municípios que assumiram 151 escolas, 1460 classes, 49.429 alunos e 949 professores efetivos. (Escriba, 1996, s/n)

Ainda segundo o decreto, a absorção das escolas pelos municípios deveria levar em conta a capacidade "técnica-administrativa-financeira de cada município", cabendo ao governo estadual cooperar por meio da "instituição do processo de avaliação do sistema de ensino, com a finalidade de proceder às correções necessárias para implantação do Programa" (artigo 4).

0 convênio insiste na idéia de ação compartilhada ${ }^{6}$ entre as duas efferas governamentais, cabendo à SEE: a assistência técnica para a elaboração do plano municipal de educação, estatuto e plano de carreira do magistério, regimento escolar, assessoria para instalação do CME, além de outros instrumentos e mecanismos que se fizessem necessários para a gestão da rede escolar.

Segundo o material elaborado pela Secretaria da Educação para subsidiar os municípios na implementação de seus sistemas, os municípios "constituem-se parceiros privilegiados da gestão educacional. Parceria significa igualdade de condições para propor, debater, implementar políticas e estratégias, assumir e compartilhar responsabilidades" (sEe, 1997, p. 9).

Q uanto ao pessoal, a secretaria estadual comprometia-se a transferir funcionários ${ }^{7}$ técnicos, administrativos e docentes necessários, co-respon- 
sabilizando-se por sua capacitação. 0 valor do convênio seria estabelecido mediante aporte de recursos da SEe e contrapartida do município. 0 convênio indicava também que os recursos seriam repassados em função de Plano de Trabalho baseado no Decreto n. 40.722, de 20 de março de 1996, que dispõe sobre a prévia autorização do governador para celebração de convênios no âmbito da administração centralizada e autárquica. A prestação de contas seria feita junto ao Tribunal de Contas do Estado e a vigência do convênio, prevista para cinco anos, podendo ser desfeita, por acordo entre as partes ou denúncia por desinteresse de qualquer das partes, com aviso prévio de 90 dias.

Em matéria publicada no mesmo ano em que a SEE instituiu o programa de parceria, o jornal 0 Estado de S. Paulo (1996, p. B-8) informava que

A Secretaria Estadual de Educação quer intensificar a municipalização da rede escolar de 10 grau. A meta é passar às prefeituras todos os alunos de 5 milhões de alunos nos próximos dois anos. Com elas as administrações municipais vão receber todos os professores efetivos e os prédios onde funcionam as unidades.

Apesar de paulatina, é perceptível a transferência de matrículas da rede estadual para os municípios. $0 \mathrm{~s}$ resultados expressos nos dados de matrícula total do ensino fundamental indicam o desempenho, no primeiro governo de $\mathrm{M}$ ario Covas, do processo de municipalização por meio de parcerias. Há que se frisar o "estímulo" dado pelo fUndef a partir de 1998. A tabela a seguir permite a visualização do processo de transferência de matrículas:

\section{Tabela 3}

(M atrículas no ensino fundamental por dependência administrativa)

\begin{tabular}{|l|l|l|l|l|l|l|l|l|l|l|}
\hline & 1996 & 1996 & 1997 & 1997 & 1998 & 1998 & $\mathbf{1 9 9 9}$ & $\mathbf{1 9 9 9}$ & $\mathbf{2 0 0 2}$ & $\mathbf{2 0 0 2}$ \\
\hline Estado & 5078538 & $87,5 \%$ & 4634560 & $81,2 \%$ & 4436407 & $78,8 \%$ & 3864835 & $72,8 \%$ & 3285131 & $62,9 \%$ \\
\hline M unicípio & 726704 & $12,5 \%$ & 1075850 & $18,8 \%$ & 1194819 & $18 \%$ & 1511184 & $27,2 \%$ & 1935951 & $37,1 \%$ \\
\hline T otal & 5805242 & $100 \%$ & 5710410 & $100 \%$ & 5731226 & $100 \%$ & 5376019 & $100 \%$ & 5221082 & $100 \%$ \\
\hline
\end{tabular}

Fonte: CIE/SEE 
Se em 1996, a rede estadual atendia $87,5 \%$ da demanda para 0 ensino fundamental, em 2002, o percentual de alunos atendido por essa rede era de $62,9 \%$, contra $37,1 \%$ das redes municipais, indicando a manutenção da tendência de transferência deste nível de ensino para os municípios.

Em meados de 1996, outro decreto ${ }^{8}$ estabeleceu que as reformas ou construções de prédios escolares passassem a ser enquadradas no plano de obras estaduais no município, obedecendo às normas pedagógicas da SEE e às orientações técnicas da FDE. N o mesmo período, o D ecreto $n$. 40.903, de 12 de julho de 1996, autorizava a SEE a celebrar convênios com 103 municípios para aquisição de veículos para transporte de alunos, tendo por público-alvo alunos do ensino fundamental residentes na zona rural. Também em conseqüência dos convênios, a SEE poderia, transitoriamente, doar materiais inservíveis e/ou excedentes aos municípios que assumissem classes "desativadas" da rede estadual.

Com a aprovação da nova LDB, O CEE, mantendo a tendência de transferência do ensino fundamental para os municípios, traça, por meio da Indicação n. 1/97, diretrizes para a constituição dos Sistemas M unicipais de Ensino, ${ }^{9}$ segundo as quais haveria dois caminhos para a ampliação da oferta de vagas dessa etapa da educação básica. 0 primeiro, por meio da criação de seu próprio sistema, de acordo com as orientações expressas na Lei Estadual n. 9.143/95 e em outros documentos legais elaborados sobre 0 assunto pelo $\mathrm{CEE}^{10} \mathrm{O}$ segundo seria integrar-se ao sistema estadual, para o que o município deveria procurar a SEE. Embora a LD B permitisse ainda uma terceira opção, a composição com o Estado de um sistema único para o atendimento ao ensino fundamental, essa possibilidade sequer chegou a ser tratada.

Para a criação dos sistemas municipais no estado de São Paulo e de outras formas de "colaboração" entre estado e municípios para a oferta da educação básica, segundo o Colegiado, o critério básico a ser seguido pelas duas esferas governamentais deveria ser o "respeito ao interesse geral". Em vista disso, a autonomia do sistema municipal deveria "valorizar o espírito de cooperação", por meio da "sintonia" entre as decisões na órbita municipal e as diretrizes de âmbito estadual. Por outro lado, o CEe advertia o sistema estadual para que respeitasse as "aspirações legítimas dos municípios, criando condições para a busca de soluções próprias" por parte dos sistemas municipais. 
Em 1998, outra alteração nas normas para estabelecimento das parcerias, por meio de convênios entre estado e municípios, resultou do D ecreto n. 43.072, de 4 de maio de 1998, que disciplinou a questão após a aprovação do FUNDEF. De acordo com o decreto, a continuidade do Programa de Parceria Educacional entre Estado e M unicípios passa a se viabilizar mediante "a transferência de alunos e recursos materiais e 0 afastamento de pessoal docente, técnico e administrativo, que implicará no repasse de recursos originários" do FUNDEF.

A partir deste momento, a lógica da descentralização da oferta do ensino fundamental no estado de São Paulo passaria a ser a do Fundo, cabendo à SEE a defesa dos "benefícios" da municipalização e do FUNDEF.

0 conteúdo de uma reportagem publicada no jornal 0 Estado de S. Paulo ilustra as considerações efetuadas até aqui. Sob o título "C resce parceria entre Estado e setor privado", a matéria apresenta pinceladas do que consistiria uma das veias da reforma da educação no Brasil, a partir de posições defendidas por Patrício M illan, coordenador para programas sociais do BIRD, quando em visita à Braślila.

Segundo as regras do BIRD, instituição que financia projetos para o desenvolvimento do Terceiro M undo, o governo brasileiro aposta na municipalização do ensino de crianças de 7 a 14 anos como ponto de partida da re forma. (...) M esmo no ensino municipalizado, a reformainclui a integração entre iniciativa privada e comunidade em modelos de parcerias para criar novas fontes de financiamento. (0 Estado deS. Paulo, 1998, p. A-10)

Segundo a reportagem "em São Paulo, a Secretaria Estadual de Educação desenvolve uma espécie de plano piloto" (idem, ibid.).

\section{Considerações finais}

A Secretaria de Educação talvez tenha sido a esfera da administração estadual que, no período analisado, mais radicalmente levou adiante a pretensão de alterações no aparelho do Estado, proclamada pelo governo de Fernando Henrique Cardoso, mediante o Plano de Reforma no Aparelho do Estado (1995), e assumida pelo governo estadual paulista. Para tanto, levou a cabo um projeto de reforma na educação paulista deflagrado em sua totalidade desde o primeiro dia de governo, para o que, em nome da racionalização dos investimentos em educação, cerceou qualquer possibilidade de negociação com setores divergentes. 
A mudança no papel atribuído ao estado aparece também na opção pelo "caráter redistributivo da ação estatal", como forma de se alcançar uma possível eqüidade na oferta do serviço prestado. Para tanto, a SEE autoproclamava-se a instância responsável por elaborar a política educacional para o estado, dado o conseqüente papel de liderança no setor que o atendimento, no início da década de 1990 , de $80 \%$ da demanda do ensino fundamental e médio Ihe reservava. É interessante observar que foi justamente 0 elemento identificado como responsável pelo baixo desempenho da educação no estado - o gigantismo da rede - que legitimou o referido papel de liderança.

Parece pertinente lembrar que perspectivas pautadas numa racionalidade meramente econômica compuseram a agenda das reformas educativas nos anos de 1990. Com vistas a subsidiar opções de políticas otimizadoras, tais perspectivas assentavam-se em resultados de correlações e pesquisas organizadas ou selecionadas por agências internacionais a respeito do impacto "dos diferentes insumos" educacionais sobre a qualidade do produto da escola. De modo geral, os estudos indicavam que insumos como aumento de salário, diminuição do número de alunos por classe e natureza da formação prévia dos profissionais da educação representavam um esforço de investimento não justificável em países em desenvolvimento, dado que medidas menos custosas, como distribuição de livro didático e descentralização da gestão, também incidiriam positivamente sobre o desempenho dos alunos nos exames de sondagem da qualidade do ensino (cf. Lockeheed \& Vespoor, 1989; CEPAL-Unesco, 1992).

Inserida nessa lógica, a opção tomada pela SEE - reorganização das escolas da rede estadual de ensino - instituiu a separação em prédios diferentes das quatro primeiras séries do ensino fundamental e das quatro últimas séries dessa modalidade de ensino e a separação desta modalidade da subseqüente, 0 ensino médio. Segundo o documento que apresentou as diretrizes governamentais para a educação paulista, a reorganização das escolas representaria um dos mecanismos necessários ao aumento da racionalização da rede. Antes que uma medida de caráter pedagógico, como foi veiculado pela SEE, a reorganização das escolas visava à diminuição de gastos e de desperdícios do sistema, expressa em um hipotético excessivo número de professores e de salas. Dividiram-se as escolas e os níveis de ensino; quebrou-se, ao meio, a escola de oito anos e pulverizou-se, pelo interior do estado, uma infinidade de arranjos institucionais para garantir a oferta, pelos municípios, do ensino fundamental. 
Em nome do aumento da eficiência e da eficácia da rede estadual, justificaram-se as medidas de descentralização tomadas pela Secretaria que implicaram o processo ainda em curso de transferência do ensino fundamental para grande parte dos municípios de São Paulo. Essa perspectiva descentralizadora de caráter intergovernamental (G alvão, 1997) resultou no aprofundamento da tendência do governo estadual em se de sobrigar da oferta de parte da educação básica, ainda que mantendo sobre seu controle a definição dos parâmetros básicos para seu funcionamento: termos dos convênios, padrão de avaliação etc.

0 resultado das intervenções do governo estadual expressou-se, assim, no redesenho da rede estadual do ensino e na conseqüente alteração da gestão e da oferta da educação básica no estado. São mudanças inscritas no que, durante os anos de 1990, se convencionou chamar de reforma e racionalização do aparelho do Estado, a faceta anti-social de muitas das políticas adotadas no período.

Recebido em janeiro de 2006 e aprovado em março de 2007.

\section{$\mathrm{N}$ otas}

1. Segundo o Fórum Estadual em D efesa da Escola Pública e a APEoEsp, nem todas as escolas tiveram acesso a este documento.

2. O ocorrido no município de Rio Claro é exemplo dessa orientação, conforme trabalho de Adrião e Silveira (2005).

3. Lembramos que a medida é anterior à LD B e se baseia no artigo 71 da Lei n. 5.692/71.

4. 0 mesmo decreto trata dos convênios com Associações de Pais e M estres (APM S). N este, os signatários são a secretária e o diretor executivo das APM S que, no caso de São Paulo, é o diretor da escola.

5. 0 artigo 240 fixa para os municípios a prioridade no atendimento ao ensino fundamental. 0 artigo 249 prevê a colaboração entre as esferas governamentais para o oferecimento da educação básica.

6. De acordo com os artigos 211, 212 e 213 , da CF, e os já citados 240 e $\S \S 10$ e 2ํ do artigo 249, da Constituição Estadual.

7. O s profissionais da educação que atuavam nas unidades escolares transferidas, caso fossem professores, seriam remanejados para escolas próximas, quando se tratassem de especialistas ou profissionais dos setores administrativo ou operacional, seriam removidos ex-officio (Comunicado DHRU n. 7, 29 abr. 1996).

8. Decreto Estadual n. 40.904, de 12 de junho de 1996, que altera o D ecreto n. 36.546, de 15 de março de 1993, responsável por instituir o Programa de Ação Cooperativa Estado-M unicípio para construções escolares. 
9. De acordo com os artigos 11e 18 da nova LDB.

10. Del. CeE 6/95 e 9/95 e as Indicações CeE 4/95 e 6/95.

\section{Referências}

AÇÃO EDU CATIVA. Colóquio sobre a reorganização da rede estadual de ensino de São Paulo. São Paulo: A ção Educativa; Puc/sp, 1996. (Debates, 1)

ADRIÃO, T. Autonomia monitorada como eixo de mudança: padrões de gestão do ensino público paulista. 2001. Tese (D outorado) - Faculdade de Educação, Universidade de São Paulo, São Paulo.

ADRIÃO , T.; SILVEIRA, A. O Fundo de M anutenção do Ensino Fundamental e Valorização do M agistério (fund DEF) e a educação básica em São Paulo: análise de quatro municípios. Rio Claro, 2005. 19p. (mimeog.)

ARELARO, L.R. A municipalização do ensino no estado de São Paulo: antecedentes históricos e tendências. In: O LIVEIRA, $C$. et al. M unicipalização do ensino no Brasil. Belo H orizonte: Autêntica, 1999, p. 61-90.

BAN CO MUNDIAL. EI mejoramiento de la educación primaria en los países en desarrollo: un examen de las opciones de política. Washington, DC, 1989.

BAN CO MUNDIAL. EI desarrollo en la práctica: prioridades y estrategias para la educación. Washington, DC: Banco Internacional de Reconstrução e D esenvolvimento, 1996.

BAN CO MUNDIAL. O Estado num mundo em transformação; relatório sobre desenvolvimento M undial 1997. Washington, DC: Banco Internacional de Reconstrução e D esenvolvimento, 1997.

CAST RO, C.M . et al. D ealing with poor students. In: BIRDSALL, N .; SABOT, R.H . O pportunity foregone: education in Brazil. Washington, DC: Inter-American D evelopment Bank, 1996. p. 497-522.

COMISIÓN ECONÓMICA PARA AMERICA LATINA Y EL CARIBE (CEPAL). Educación y conocimiento: eje de la transformación productiva con equidad. Santiago de Chile: Cepal/un Esco, 1992. 
COSTA, M . A educação em tempos de conservadorismo. In. GentiLLI, P (O rg.). A pedagogia da exclusão: crítica ao neoliberalismo em educação. Petrópolis: Vozes, 1995. p. 43-71.

O ESTADO de S. Paulo, São Paulo, p. B-8, 28 de out. 1996.

GALVÃO, M .C.C.P. (Coord.). N ovas formas de getão dos serviç̧os públiCOS. a relação público-privada. São Paulo: FUnd AP, 1997.

LOCKHEED, M .E.; VERSPOOR, A. La mejora de la educación primaria en los países en desarrollo: un examen de las opciones de política. Washington, DC: Banco M undial, 1989.

M ART IN S, A.M. Autonomia e gestão da escola pública: entre a teoria e a prática. 2001. Tese (D outorado) - Faculdade de Educação, U niversidade Estadual de Campinas, Campinas.

M AXIM ILIAN O , A.C.A. Além da hierarquia: como implantar estratégias participativas para administrar a empresa enxuta. São Paulo: Atlas, 1995.

MELLO, G.N . Autonomia da escola: possibilidades, limites e condições. In: GOM ES, C.A.; AM ARAL SOBRIN H O, J. (O rg.). Q ualidade, eficiência e eqüidade na educação básica. Brasília, DF: IPEA, 1992. p. 175-206. (IPEA, n. 136).

M ELLO , G .N .; SI LVA, R.N . M udanças nos padrões de gestão educacional no contexto da reforma do Estado: análise de doze estudos de caso. In: XAVIER, A.C.R. et al. (O rg.). G etão educacional: experiências inovadoras. Brasília, DF: IPEA, 1995. (IPEA, n. 145).

PEREIRA, P. Cresce parceria entre Estado e setor privado. 0 Estado de S. Paulo, São Paulo, p. A-10, 1o mar. 1998.

PERONI, V. A redefinição do papel do Estado e a política educacional no Brasil dos anos 90. Sã̃o Paulo: Xamã, 2003.

REVISTA ESCRIBA. São Paulo: Governo do Estado, 1996.

REVISTA ESCRIBA. São Paulo: Governo do Estado, 1997.

SÃO PAULO (Estado). Secretaria de Estado da Educação de São Paulo (seE). Coordenadoria de Estudos e N ormas Pedagógicas. Legislação 
de ensino de $1^{0}$ e $2^{\circ}$ graus: Fundamental e médio estadual. São Paulo: SEE/CENP, 1995.

SÃO PAULO (Estado). Secretaria de Estado da Educação de São Paulo (SEE). D ecreto Estadual n. 40.473, de 21 de novembro de 1995. Institui o Programa de Reorganização das escolas da Rede Estadual e dá providências correlatas. Diário O ficial do Estado de São Paulo, São Paulo, v. 105, n. 222, 22 nov. 1995.

SÃO PAULO (Estado). Secretaria de Estado da Educação de São Paulo (SEE). D ecreto Estadual n. 40.673, de 16 de fevereiro de 1996. Institui o Programa de Parceria Educação do Estado-M unicípios para atendimento do Ensino Fundamental. Diário O ficial do Estado de São Paulo, São Paulo, v. 106, n. 33, 17 fev. 1996.

SÃO PAULO (Estado). Secretaria de Estado da Educação de São Paulo (SEE). L egislação de ensino de fundamental e médio estadual. São PauIO: SEE/CENP, 1996, 1997, 1998, 1999. Disponível em: <http:// www.educacao.sp.gov.br/projetos/parceria>. Acesso em: 21 jul. 2001.

SÃO PAULO (Estado). Secretaria de Estado da Educação de São Paulo (SEE). M udar para melhor: uma escola para criança e outra para 0 adolescente - venha conhecer. São Paulo: SEE, 1995.

SÃo PAULO (Estado). Secretaria de Estado da Educação de São Paulo (SEE). M udar para melhor: uma escola para criança e outra para o adolescente - reorganização das escolas da rede estadual. São Paulo: SEE, 1995.

SÃO PAULO (Estado). Você sabia? 4 anos de governo 1995-1998. São Paulo, maio 1999.

TEDESC O , J.C. Alguns aspectos da privatização educativa na América Latina. Estudos Avançados, São Paulo, v. 12, n. 5, maio/ago. 1991.

TEDESCO , J.C. Principais tendências regionais e internacionais. In: GEST ÃO educacional: tendências e perspectivas. São Paulo: CEN PEC, 1999. p. 41-51. 